\title{
Copolymerization and terpolymerization of carbon dioxide/ propylene oxide/phthalic anhydride using a (salen)Co(III) complex tethering four quaternary ammonium salts
}

\author{
Jong Yeob Jeon, Seong Chan Eo, Jobi Kodiyan Varghese and Bun Yeoul Lee*
}

\author{
Full Research Paper \\ Address: \\ Department of Molecular Science and Technology, Ajou University, \\ Suwon 443-749 Korea \\ Email: \\ Bun Yeoul Lee* - bunyeoul@ajou.ac.kr \\ * Corresponding author \\ Keywords: \\ carbon dioxide; $\mathrm{CO}_{2}$ chemistry; cobalt complex; phthalic anhydride; \\ propylene oxide; terpolymerization \\ Beilstein J. Org. Chem. 2014, 10, 1787-1795. \\ doi:10.3762/bjoc. 10.187 \\ Received: 29 March 2014 \\ Accepted: 18 July 2014 \\ Published: 05 August 2014 \\ This article is part of the Thematic Series " $\mathrm{CO}_{2}$ Chemistry". \\ Guest Editors: W. Leitner and T. E. Müller \\ (C) 2014 Jeon et al; licensee Beilstein-Institut. \\ License and terms: see end of document.
}

\begin{abstract}
The (salen)Co(III) complex 1 tethering four quaternary ammonium salts, which is a highly active catalyst in $\mathrm{CO}_{2} /$ epoxide copolymerizations, shows high activity for propylene oxide/phthalic anhydride (PO/PA) copolymerizations and $\mathrm{PO} / \mathrm{CO}_{2} / \mathrm{PA}$ terpolymerizations. In the PO/PA copolymerizations, full conversion of PA was achieved within $5 \mathrm{~h}$, and strictly alternating copolymers of poly(1,2-propylene phthalate)s were afforded without any formation of ether linkages. In the $\mathrm{PO} / \mathrm{CO}_{2} / \mathrm{PA}$ terpolymerizations, full conversion of PA was also achieved within $4 \mathrm{~h}$. The resulting polymers were gradient poly(1,2-propylene carbonate-co-phthalate)s because of the drift in the PA concentration during the terpolymerization. Both polymerizations showed immortal polymerization character; therefore, the molecular weights were determined by the activity ( $\mathrm{g} / \mathrm{mol}-\mathbf{1})$ and the number of chain-growing sites per $\mathbf{1}$ [anions in 1 (5) + water (present as impurity) + ethanol (deliberately fed)], and the molecular weight distributions were narrow $\left(M_{\mathrm{w}} / M_{\mathrm{n}}, 1.05-1.5\right)$. Because of the extremely high activity of $\mathbf{1}$, high-molecular-weight polymers were generated $\left(M_{\mathrm{n}}\right.$ up to 170,000 and 350,000 for the $\mathrm{PO} / \mathrm{PA}$ copolymerization and $\mathrm{PO} / \mathrm{CO}_{2} / \mathrm{PA}$ terpolymerization, respectively). The terpolymers bearing a substantial number of PA units $\left(f_{\mathrm{PA}}, 0.23\right)$ showed a higher glass-transition temperature $\left(48^{\circ} \mathrm{C}\right)$ than the $\mathrm{CO}_{2} / \mathrm{PO}$ alternating copolymer $\left(40^{\circ} \mathrm{C}\right)$.
\end{abstract}

\section{Introduction}

Carbon dioxide $\left(\mathrm{CO}_{2}\right)$ can be utilized to prepare aliphatic polycarbonates through coupling reactions with epoxides [1-6]. The pioneering work for this copolymerization was introduced by Inoue in 1969 [7]. Eventually, a highly active and efficient cata- lyst was developed based on the concept of combining (salen)Co(III) units with quaternary ammonium salts in a molecule [8-12]. The highly efficient catalyst (1 in Scheme 1) showed a high turnover frequency (TOF, 16,000 $\mathrm{h}^{-1}$ ), high 

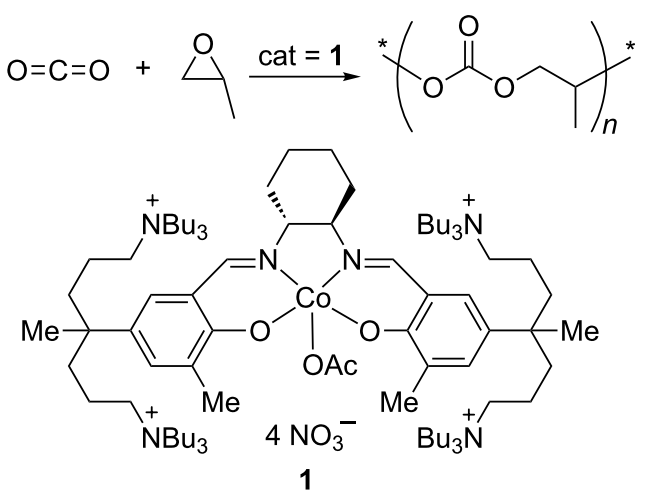

Scheme 1: Synthesis of poly(propylene carbonate) (PPC) using catalyst 1.

molecular weight $\left(M_{\mathrm{n}}\right.$, up to 300,000$)$, and good selectivity ( $>99 \%)$. These promising performances motivated to construct a continuous-process pilot plant in industry [13]. Currently, many hurdles in the preparation of $\mathbf{1}$ on a large scale have been overcome, and an economical synthesis on the $100 \mathrm{~kg}$ scale has been achieved [14-16], along with precise control of the molecular weight and chain topology, facilitating the applications of these attractive materials [14,17-19]. Now, the production of poly(propylene carbonate) (PPC) using catalyst $\mathbf{1}$ is at the stage of the final decision regarding a commercial investment. Another success story using double metal cyanide (DMC) catalysts has been reported recently [20]. The DMC catalysts provided low-molecular-weight $\mathrm{CO}_{2} / \mathrm{PO}$ copolymers containing significant numbers of ether linkages [21,22].

PO and ethylene oxide (EO) are bulk chemicals produced annually on the million-ton scale, and the focus in industry has been on $\mathrm{CO}_{2} / \mathrm{PO}$ and $\mathrm{CO}_{2} / \mathrm{EO}$ copolymerizations. Catalyst $\mathbf{1}$ is also highly active in $\mathrm{CO}_{2} / \mathrm{EO}$ copolymerizations [23]. Even though the $\mathrm{CO}_{2} / \mathrm{PO}$ or $\mathrm{CO}_{2} / \mathrm{EO}$ copolymer itself shows some advantageous properties such as biodegradability, good adhesiveness, good barrier properties, and clean burning properties, the incorporation of a third monomer has also been pursued to improve the properties and hence facilitate its use in more widespread applications. For example, the terpolymerization of $\mathrm{CO}_{2} /$ $\mathrm{PO} /$ cyclohexene oxide (CHO) was successful, providing resins, of which the glass-transition temperatures $\left(T_{\mathrm{g}}\right)$ were modulated in the range of $50-100{ }^{\circ} \mathrm{C}$ according to the mole fraction of the incorporated $\mathrm{CHO}[24,25]$. However, the feeding of a third monomer such as $\mathrm{CHO}$ gives rise to intrinsic problems in terms of commercial operation. The third monomer is not completely consumed, and the remaining $\mathrm{CHO}$ should be recovered and recycled, which is a severe burden because of its high boiling point $\left(130^{\circ} \mathrm{C}\right)$. Moreover, the toxic $\mathrm{CHO}$ should be removed completely from the resin for use in our daily life. In this work, we demonstrate the complete incorporation of the third monomer of phthalic anhydride (PA) in $\mathrm{CO}_{2} / \mathrm{PO}$ copolymerizations using catalyst 1 .

\section{Results and Discussion PO/PA copolymerizations}

Alternating copolymerizations of epoxides and cyclic anhydrides using a diiminate zinc catalyst as well as a chromium(III) salen complex have been reported [26,27]. Long reaction times $(>10 \mathrm{~h})$ were needed to reach full conversion, and the average molecular weights were in the region of several ten thousand. When a zinc glutarate catalyst was used in PO/PA copolymerization, significant numbers of ether linkages were generated through consecutive PO incorporation [28].

When PA (1.00 g) and PO (10.4 g) were reacted using catalyst 1 $(3.0 \mathrm{mg} ; 1 / \mathrm{PA} / \mathrm{PO}=1: 3,750: 100,000)$ at $80{ }^{\circ} \mathrm{C}$ for $3 \mathrm{~h}, 100 \%$ conversion of PA was achieved (entry 1 in Table 1). The ${ }^{1} \mathrm{H}$ NMR spectrum indicated that no PA remained in the resulting solution, and that the generated polymer was strictly alternating with no ether linkages (Scheme 2, Figure 1(A)). The isolated polymer mass was $1.39 \mathrm{~g}$, in exact agreement with that calculated $(1.39 \mathrm{~g})$ on the basis of full conversion of $1.0 \mathrm{~g}$ PA to the strictly alternating PO/PA copolymer. Three aromatic signals were observed in the ${ }^{1} \mathrm{H}$ NMR spectra at 7.71, 7.68, and $7.50 \mathrm{ppm}$ in 1:1:2 ratios (Figure $1(\mathrm{~A})$ ). The $\mathrm{OCH}(\mathrm{Me})$ signal was observed at $5.35 \mathrm{ppm}$, while the $\mathrm{CH}_{2} \mathrm{O}$ signal was observed at $4.3-4.5 \mathrm{ppm}$. When a larger amount of PA $(2.0 \mathrm{~g})$ was added, the conversion of PA was $76 \%$ after $3 \mathrm{~h}$ (Table 1, entry 2 ) and $96 \%$ after 4.5 h (Table 1, entry 3), but full conversion of PA was achieved after running the copolymerization for $5.0 \mathrm{~h}$ (Table 1, entry 4). When $3.0 \mathrm{~g}$ PA was added, the conversion of PA was very low (16\%), and after polymerization, a lot of unreacted PA was deposited as a solid. The solubility of PA in PO was limited; $3.0 \mathrm{~g}$ of PA might not dissolve fully in $10 \mathrm{~g}$ of PO even at a high temperature of $80{ }^{\circ} \mathrm{C}$. Catalyst residues were removed completely through filtration with a short pad of silica gel after the polymerization. After filtration, the light orange solution became colorless, and the isolated polymer was also colorless (see Supporting Information File 1). If PA was not fully converted, the polymers were obtained as admixtures with unreacted PA (Table 1, entries 2 and 3).

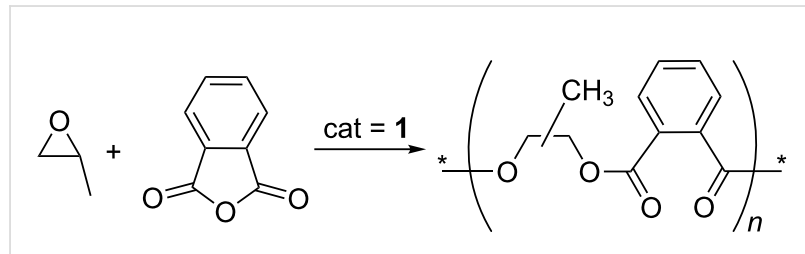

Scheme 2: PO/PA alternating copolymerization. 


\begin{tabular}{|c|c|c|c|c|c|c|c|c|c|}
\hline Entry & $\begin{array}{l}\text { PA } \\
\text { (g) }\end{array}$ & $\begin{array}{r}\mathrm{EtOH} \\
(\mathrm{mg})\end{array}$ & $\begin{array}{r}\text { Time } \\
(\mathrm{h})^{b}\end{array}$ & $\begin{array}{c}\text { PA conversion } \\
(\%)\end{array}$ & $\begin{array}{r}\text { Yield }^{c} \\
\text { (g) }\end{array}$ & $\begin{array}{r}\text { Activity } \\
\text { (Kg/g-cat) }\end{array}$ & $M_{\mathrm{n}}{ }^{\mathrm{d}}$ & $M_{\mathrm{w}} / M_{n}^{\mathrm{d}}$ & $\begin{array}{l}T_{\mathrm{g}}^{\mathrm{e}} \\
\left({ }^{\circ} \mathrm{C}\right)\end{array}$ \\
\hline 1 & 1.0 & 0 & 3.0 & 100 & 1.39 (1.39) & 0.46 & 59,000 & 1.61 & 65 \\
\hline 2 & 2.0 & 0 & 3.0 & 76 & (2.2) & $(0.73)$ & 80,000 & 1.26 & 62 \\
\hline 3 & 2.0 & 0 & 4.5 & 96 & (2.7) & $(0.90)$ & 116,000 & 1.27 & 65 \\
\hline 4 & 2.0 & 0 & 5.0 & 100 & $2.70(2.78)$ & 0.90 & 167,000 & 1.21 & 65 \\
\hline 5 & 2.0 & 5.0 & 5.0 & 100 & $2.70(2.78)$ & 0.90 & 17,000 & 1.43 & 63 \\
\hline 6 & 2.0 & 10 & 5.0 & 100 & $2.63(2.78)$ & 0.88 & 11,000 & 1.42 & 60 \\
\hline 7 & 2.0 & 15 & 5.0 & 100 & $2.54(2.78)$ & 0.84 & 9,000 & 1.40 & 58 \\
\hline 8 & 2.0 & 20 & 5.0 & 100 & $2.48(2.78)$ & 0.83 & 6,000 & 1.40 & 55 \\
\hline
\end{tabular}

aPolymerization conditions: $\mathrm{PO}(10.4 \mathrm{~g}, 180 \mathrm{mmol})$, catalyst $1(3.0 \mathrm{mg}, 1.8 \mu \mathrm{mol})$, temperature $\left(80{ }^{\circ} \mathrm{C}\right) .{ }^{\mathrm{b}}$ Including heating time of ca. $50 \mathrm{~min}$. ${ }^{\mathrm{C}} \mathrm{Values}$ in parentheses calculated from the conversion. ${ }^{\mathrm{d} D}$ Determined on GPC using a polystyrene standard. ${ }^{\mathrm{e}}$ Determined on DSC.

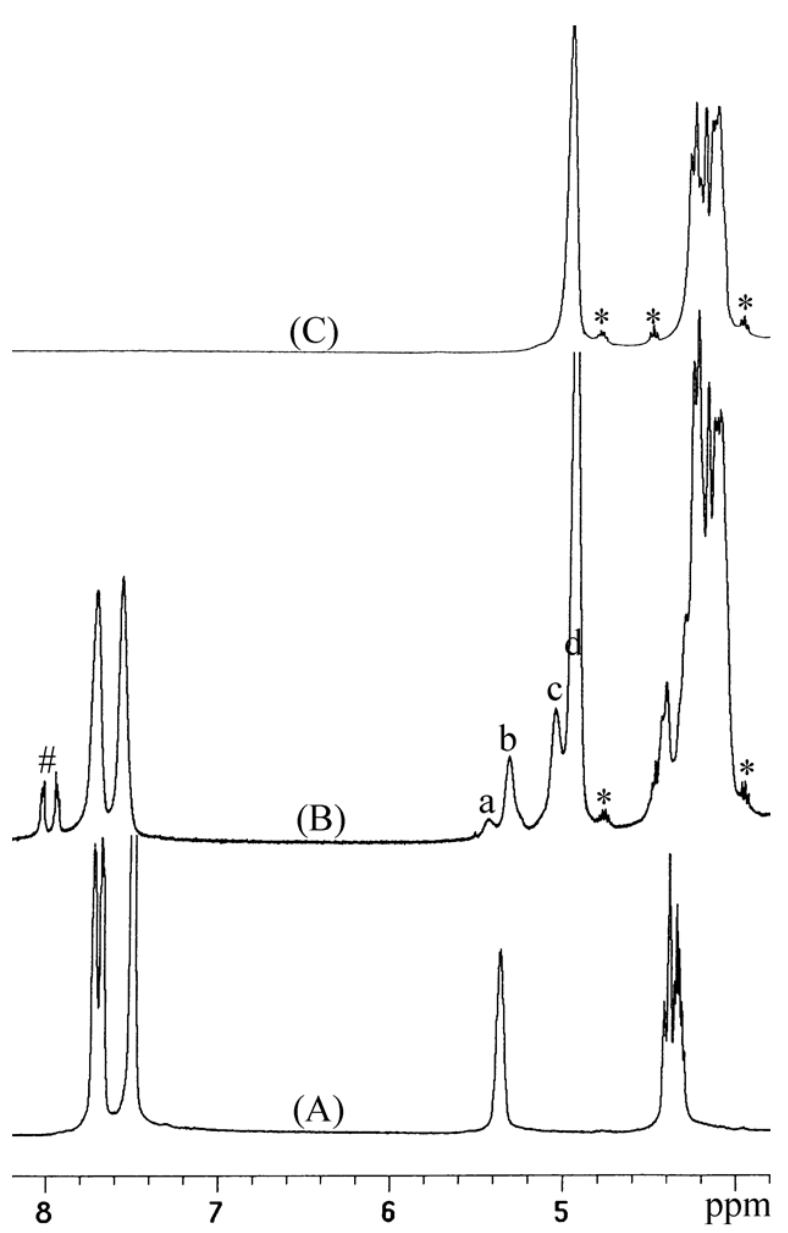

Figure 1: ${ }^{1} \mathrm{H}$ NMR spectrum of crude products in the PO/PA alternating polymerization ( $\mathrm{A}$, entry 1 in Table 1 ), $\mathrm{PO} / \mathrm{CO}_{2} / \mathrm{PA}$ terpolymerization ( $\mathrm{B}$, entry 3 in Table 2), and $\mathrm{CO}_{2} / \mathrm{PO}$ alternating copolymerization (C) ("a" signal for ester- $\mathrm{CH}(\mathrm{Me}) \mathrm{CH}_{2}$-ester; "b" signal for ester$\mathrm{CH}(\mathrm{Me}) \mathrm{CH}_{2}$-carbonate; "c" signal for ester- $\mathrm{CH}_{2} \mathrm{CH}(\mathrm{Me})$-carbonate; "d" signal for carbonate- $\mathrm{CH}_{2} \mathrm{CH}(\mathrm{Me})$-carbonate; "*" signals for propylene carbonate; "\#" signals for unreacted PA).
At the full conversion of $1.0 \mathrm{~g}$ PA, the number average molecular weight $\left(M_{\mathrm{n}}\right)$ of the resulting polymer was 59,000 (Table 1, entry 1). Upon increasing the PA feed amount to $2.0 \mathrm{~g}$ and achieving full conversion, a high-molecular-weight polymer with $M_{\mathrm{n}}=167,000$ was obtained (Table 1 , entry 4). As the reaction time (and consequently, the PA conversion) increased, the number average molecular weight $\left(M_{\mathrm{n}}\right)$ increased gradually with a narrow molecular weight distribution $\left(M_{\mathrm{w}} / M_{\mathrm{n}}\right.$ ca. 1.2) preserved in all cases, indicating living or immortal polymerization (Table 1, entries 2-4). Bimodal distributions were observed in the GPC curves (Figure 2). The peak molecular weight in the high-molecular-weight mode was always twice that in the lowmolecular-weight mode. The chains in the high-molecularweight mode were attributed to those grown biaxially from water, which was present as an impurity, while those in the lowmolecular-weight mode were grown from the nitrate and acetate anions in $\mathbf{1}$. The numbers of polymer chains generated per $\mathbf{1}$, which was calculated from the yield $(\mathrm{g})$ and $M_{\mathrm{n}}$ values [yield $/\left(M_{\mathrm{n}} \times\right.$ (mole of 1)], were 13, 15, 13, and 9 for the samples in Table 1, entries 1-4, respectively. These numbers were roughly in agreement with the sum of the number of anions in 1 (5) and the number of water molecules per 1 present as an impurity $(8,10,8$, and 4 , respectively). The portion of the high-molecular-weight mode (that is, the portion of chains grown from water molecules) relative to the portion of the lowmolecular-weight mode decreased in the GPC curves in the order of entries 2, 3, and 4 (see Supporting Information File 1). This order was in accord with the number of water molecules calculated above from the yield and $M_{\mathrm{n}}$ values $(10,8$, and 4 , respectively). These observations indicated that the polymer chains grew uniformly from the anions in $\mathbf{1}$ and water molecules with immortal polymerization character. Water molecules might be incorporated into the polymerization system from various sources such as $\mathrm{PO}, \mathrm{CO}_{2}$ gas, catalyst, and the reactor surface. The amount fluctuated batch by batch in the lab scale polymerization. 


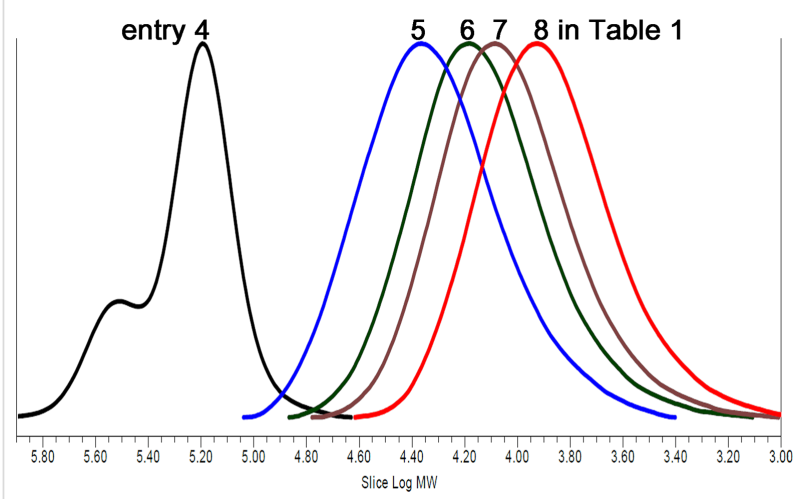

Figure 2: GPC curves of the PO/PA copolymers.

Upon the addition of ethanol, which was expected to act as a chain-transfer agent, the $M_{\mathrm{n}}$ values decreased significantly and were regulated precisely by the amount of ethanol fed (Table 1 , entries 5-8). With $5.0 \mathrm{mg}$ of ethanol fed at the PA feeding of $2.0 \mathrm{~g}$, full PA conversion was achieved by running for $5 \mathrm{~h}$, and the $M_{\mathrm{n}}$ value of the resulting polymer was 17,000 , indicating that the ethanol worked well as a chain-transfer agent (Table 1, entry 5). As the amount of ethanol was increased to 10, 15, and $20 \mathrm{mg}$, full conversions were also achieved in $5 \mathrm{~h}$, and the $M_{\mathrm{n}}$ values decreased systematically to $11,000,9,000$, and 6,000 , respectively. The number of polymer chains per $\mathbf{1}$, calculated from the yield and $M_{\mathrm{n}}$ values [yield/ $\left(M_{\mathrm{n}} \times(\right.$ mole of 1$\left.)\right]$, were $92,141,173$, and 259 for the samples obtained with $5,10,15$, and $20 \mathrm{mg}$ ethanol feeding, respectively. These numbers were in rough agreement with the sum of the number of ethanol molecules per $1(60,120,180$, and 240 , respectively) and the number of anions in 1 (5). The polymer chains were grown uniformly from the fed ethanol and the anions in $\mathbf{1}$ with immortal polymerization character. The portion of the chains grown biaxially from impurity water molecules was relatively small, and unimodal distributions were observed when ethanol was fed. The $T_{\mathrm{g}}$ value of the PO/PA copolymer was $65^{\circ} \mathrm{C}$ when the molecular weight was high (mostly $M_{\mathrm{n}}>80000$, Table 1 , entries $1-4)$, and decreased gradually from $63{ }^{\circ} \mathrm{C}$ to $55^{\circ} \mathrm{C}$ as $M_{\mathrm{n}}$ was lowered from 17,000 to 6,000 (Table 1 , entries 5-8).

\section{$\mathrm{PO} / \mathrm{CO}_{2} / \mathrm{PA}$ terpolymerizations}

The terpolymerization of $\mathrm{CHO} / \mathrm{CO}_{2} /$ diglycolic anhydride using a diiminate zinc catalyst has been reported. Here, the block copolymer of poly(ester-block-carbonate) was formed through the faster reaction of $\mathrm{CHO} /$ anhydride coupling, and after complete conversion of the anhydride, the carbonate block was grown by $\mathrm{CO}_{2} / \mathrm{CHO}$ coupling [29]. Porphyrin $\mathrm{Al}$ or $\mathrm{Cr}$ (III) complexes also generated block copolymers in $\mathrm{PO} / \mathrm{CO}_{2} / \mathrm{PA}$ terpolymerizations [30]. The terpolymerizations of $\mathrm{CHO} / \mathrm{CO}_{2} /$ $\mathrm{PA}$ and $\mathrm{PO} / \mathrm{CO}_{2} /$ maleic anhydride using a zinc glutarate catalyst have also been reported, where random copolymers containing some ether linkages were generated [28,31].

When $\mathrm{CO}_{2}$ gas was also pressurized under the PO/PA copolymerization conditions [PA (1.00 g), PO (10.4 g), 1 (3.0 mg; 1/ $\mathrm{PA} / \mathrm{PO}=1: 3,750: 100,000), 80{ }^{\circ} \mathrm{C}, 3 \mathrm{~h}$ ], all the fed PA was consumed (entry 4, Table 2). No signals due to unreacted PA were observed in the ${ }^{1} \mathrm{H}$ NMR spectrum of the resulting crude product dissolved in THF- $d_{8}$, in which both $\mathrm{PA}$ and the resulting polymer were freely soluble. Upon shortening the reaction time to $1.5,2.0$, and $2.5 \mathrm{~h}$, unreacted PA signals were observed at 8.0 and $7.9 \mathrm{ppm}$ along with the resulting polymer signals (Figure 1(B)). In all cases, negligible amounts of propylene carbonate were generated (less than $2 \mathrm{~mol} \%$ per consumed PO) and no ether linkages were formed (Scheme 3 ). The conversions of PA were calculated simply from the ${ }^{1} \mathrm{H}$ NMR spectra by using the formula $\left(I_{7.5-7.8}\right) /\left(I_{7.5-7.8}+I_{7.9-8.1}\right)$, where $I$ is the integrated value of the region defined by the subscript. As the reaction time increased, the PA conversion increased (Table 2, entries 1-4), and full conversion of PA was achieved with the formation of $6.5 \mathrm{~g}$ of polymer at a reaction time of $3.0 \mathrm{~h}$ (including the heating time of ca. $50 \mathrm{~min}$ ). The formation of $6.5 \mathrm{~g}$ of polymer corresponded to a commercially acceptable high activity of $2.2 \mathrm{~kg}$-polymer/g-catalyst. The $\mathrm{CO}_{2}$ pressure decreased monotonously from 35 to 32 bar up to the cutoff time of $3 \mathrm{~h}$, indicating that the catalyst was not deactivated during the polymerization. The turnover number $(\mathrm{TON}=$ mole of consumed $\mathrm{PO} /$ mole of $\mathbf{1}$ ) and turnover frequency (TOF) at the full PA conversion were calculated to be 32,000 and $12,000 \mathrm{~h}^{-1}$, so the performance of $\mathbf{1}$ was not deteriorated by feeding PA. In the absence of PA (that is, in $\mathrm{CO}_{2} / \mathrm{PO}$ copolymerizations), catalyst 1 showed a TOF of approximately $16,000 \mathrm{~h}^{-1}$.

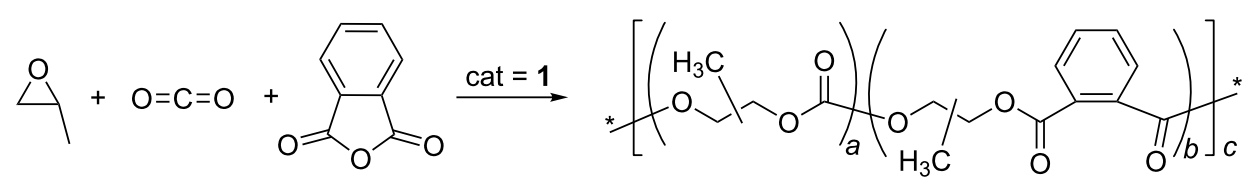


Table 2: $\mathrm{CO}_{2} / \mathrm{PO} / \mathrm{PA}$ terpolymerization results with catalyst 1. $^{\mathrm{a}}$

\begin{tabular}{|c|c|c|c|c|c|c|c|c|c|c|}
\hline Entry & $\begin{array}{l}\text { PA } \\
(g)\end{array}$ & $\begin{array}{c}\mathrm{EtOH} \\
(\mathrm{mg})\end{array}$ & $\begin{array}{l}\text { Time } \\
(\mathrm{h})^{\mathrm{b}}\end{array}$ & $\begin{array}{c}\text { PA } \\
\text { Conversion } \\
(\%)\end{array}$ & $f_{\mathrm{PA}}{ }^{\mathrm{C}}$ & $\begin{array}{l}\text { Yield }^{d} \\
\quad(g)\end{array}$ & $\begin{array}{c}\text { Activity } \\
\text { (Kg/g-cat.) }\end{array}$ & $M_{\mathrm{n}}{ }^{\mathrm{e}}$ & $M_{\mathrm{w}} / M_{n}^{\mathrm{e}}$ & $\begin{array}{c}T_{g}^{f} \\
\left({ }^{\circ} \mathrm{C}\right)\end{array}$ \\
\hline 1 & 1.0 & 0 & 1.5 & 38 & 0.12 & (2.5) & $(0.83)$ & 115,000 & 1.22 & 29,69 \\
\hline 2 & 1.0 & 0 & 2.0 & 68 & 0.23 & $(2.5)$ & $(0.83)$ & 215,000 & 1.33 & 48 \\
\hline 3 & 1.0 & 0 & 2.5 & 91 & 0.15 & $(4.7)$ & $(1.6)$ & 198,000 & 1.40 & 44 \\
\hline 4 & 1.0 & 0 & 3.0 & 100 & 0.11 & $6.5(7.0)$ & 2.2 & 381,000 & 1.27 & 41 \\
\hline 5 & 2.0 & 0 & 1.5 & 31 & 0.31 & $(1.8)$ & $(0.60)$ & 87,000 & 1.20 & 24,73 \\
\hline 6 & 2.0 & 0 & 2.0 & 86 & 0.39 & $(4.2)$ & $(1.4)$ & 193,000 & 1.22 & 43 \\
\hline 7 & 2.0 & 0 & 3.0 & 100 & 0.23 & $7.3(7.4)$ & 2.4 & 354,000 & 1.23 & 48 \\
\hline 8 & 1.0 & 5.0 & 1.5 & 50 & 0.18 & $(2.2)$ & $(0.73)$ & 19,000 & 1.08 & 25,67 \\
\hline 9 & 1.0 & 10 & 1.5 & 59 & 0.19 & (2.6) & $(0.87)$ & 10,000 & 1.06 & 25,72 \\
\hline 10 & 1.0 & 15 & 1.5 & 63 & 0.22 & (2.4) & $(0.80)$ & 8,000 & 1.07 & 25,69 \\
\hline 11 & 1.0 & 20 & 1.5 & 63 & 0.25 & $(2.2)$ & $(0.73)$ & 5,000 & 1.05 & 14 \\
\hline 12 & 1.0 & 15 & 2.0 & 80 & 0.18 & (3.6) & $(1.2)$ & 11,000 & 1.03 & 28 \\
\hline 13 & 1.0 & 15 & 2.5 & 100 & 0.13 & $5.7(5.9)$ & 1.9 & 16,000 & 1.03 & 39 \\
\hline 14 & 1.0 & 15 & 3.0 & 100 & 0.12 & $6.4(6.3)$ & 2.1 & 19,000 & 1.03 & 39 \\
\hline 15 & 1.0 & 15 & 4.0 & 100 & 0.10 & $7.0(7.6)$ & 2.3 & 26,000 & 1.04 & 38 \\
\hline 16 & 2.0 & 15 & 3.0 & 100 & 0.24 & $6.6(7.2)$ & 2.2 & 22,000 & 1.05 & 43 \\
\hline
\end{tabular}

aPolymerization conditions: $\mathrm{PO}(10.4 \mathrm{~g}, 180 \mathrm{mmol})$, catalyst $1(3.0 \mathrm{mg}, 1.8 \mu \mathrm{mol}), \mathrm{CO}_{2}(35 \mathrm{bar}), 80^{\circ} \mathrm{C}$. ${ }^{\mathrm{b}}$ Including heating time of ca. $50 \mathrm{~min} .{ }^{\mathrm{C}} \mathrm{Mole}$ fraction of PA in the polymers determined by ${ }^{1} \mathrm{H}$ NMR spectroscopy. ${ }^{\mathrm{d}}$ Values in parentheses calculated from conversion and $f_{\mathrm{PA}}$. ${ }^{\mathrm{e}} \mathrm{Determined}$ on GPC using a polystyrene standard. 'Determined on DSC.

Catalyst residues could also be removed completely by filtration through a short pad of silica gel to provide colorless polymers (see Supporting Information File 1). The catalyst residue should be removed thoroughly because it is not only toxic, but also leads to the thermal instability of the products [32]. It was not easy to separate the generated polymer and the unreacted PA; the polymers were obtained admixed with the unreacted PA unless $100 \%$ conversion of PA was reached.

The pattern of the aromatic signals in the ${ }^{1} \mathrm{H}$ NMR spectra was different from that observed for the alternating PO/PA copolymer: just two broad signals were observed at 7.71 and $7.57 \mathrm{ppm}$ (Figure 1(B)). Four OCH(Me) signals were observed at 5.45, 5.30, 5.10, and $4.95 \mathrm{ppm}$. The large signal at $4.95 \mathrm{ppm}$ (marked "d" in Figure 1(B)) was assigned unambiguously to the carbonate- $\mathrm{CH}(\mathrm{Me}) \mathrm{CH}_{2}$-carbonate signal through comparison with the spectrum of PPC (Figure 1(C)). The signals at $5.30 \mathrm{ppm}$ (marked "b") and $5.10 \mathrm{ppm}$ (marked "c") were assigned to ester- $\mathrm{CH}(\mathrm{Me}) \mathrm{CH}_{2}$-carbonate and ester$\mathrm{CH}_{2} \mathrm{CH}(\mathrm{Me})$-carbonate, respectively. A comparatively small signal was observed at $5.45 \mathrm{ppm}$ (marked "a"), which was assigned to ester- $\mathrm{CH}(\mathrm{Me}) \mathrm{CH}_{2}$-ester. The mole fractions of PA in the polymers $\left(f_{\mathrm{PA}}\right)$ were determined from the ${ }^{1} \mathrm{H}$ NMR spectra using the equation $f_{\mathrm{PA}}=\left[\left(I_{7.5-7.8}\right) / 4\right] / I_{4.8-5.4}$, where $I_{7.5-7.8}$ and $I_{4.8-5.4}$ are the integrated values in the region 7.5-7.8 ppm (benzene- $H$ signal) and 4.8-5.4 ppm (OCHMe signal), respectively. The yields calculated from the conversion (c) and $f_{\mathrm{PA}}$ [yield $(\mathrm{g})=\left(206.19 \times y+102.08 \times y \times\left(1-f_{\mathrm{PA}}\right) /\right.$ $\left.f_{\mathrm{PA}}\right)$, where $y$ is the number of moles of consumed PA, that is, $y=($ fed PA $(\mathrm{g}) \times c) / 148.12]$, were in good agreement with the measured weights of the isolated polymers at full PA conversion (Table 2, entries 4, 7, 13-16). The $f_{\mathrm{PA}}$ values decreased gradually from 0.23 to 0.11 upon increasing the reaction time from 2.0 to $3.0 \mathrm{~h}$ (Table 2, entries 2-4). The $\mathrm{CO}_{2}$ concentration was almost unchanged at the pressure of 35-33 bar, whereas the free PA concentration in solution was gradually depleted, resulting in lower $f_{\mathrm{PA}}$ values with increased polymerization times. A deviation was observed at a very early reaction time of $1.5 \mathrm{~h}$ (Table 2, entry 1), where the $f_{\mathrm{PA}}$ value was low (0.12) even at a high PA concentration. This deviation might be attributed to the uncontrolled reaction temperature. The bomb reactor was warmed slowly using a hot oil bath $\left(80^{\circ} \mathrm{C}\right)$, reaching the desired temperature $\left(80^{\circ} \mathrm{C}\right)$ in ca. $50 \mathrm{~min}$. If the small portion of chains grown during the warming time is ignored, the generated polymers should be gradient poly(1,2-propylene carbonateco-phthalate). The chains grown in the early stages were enriched with PA units, while those grown at a later stage were enriched with or composed solely of carbonate units. When the fed PA amount was doubled to $2.0 \mathrm{~g}$, polymers with higher PA mole fractions were generated (Table 2, entries 5-7). Upon running the reaction for $3.0 \mathrm{~h}$, full conversion of PA was also achieved (Table 2 , entry 7 ). The $f_{\mathrm{PA}}$ value at this full conver- 
sion was 0.23 , which was twice that attained at the PA feeding of $1.0 \mathrm{~g}$. Related stereogradient $\mathrm{CO}_{2} / \mathrm{PO}$ copolymers have been reported, in which one end of the polymer chain is enriched with the $R$-isomer of PO, while the other is enriched with the $S$-isomer [33,34]. A related copolymer composed of aliphatic polycarbonate and aromatic polyester units [poly(1,4-butylene terephthalate-co-carbonate)], prepared by condensation polymerization of 1,4-butanediol, dimethyl terephthalate, and dimethyl carbonate, has also been reported recently $[35,36]$.

When ethanol (5.0 mg, 60 equiv/1) was fed as a chain-transfer agent with $1.0 \mathrm{~g}$ PA, faster PA consumption was observed (Table 2, entry 8). At the initial stage of $1.5 \mathrm{~h}$ including a heating time of ca. $50 \mathrm{~min}$, the PA conversion was $50 \%$ with a high $f_{\mathrm{PA}}$ value $(0.18)$ compared with that in the absence of ethanol (PA conversion, 38\%; $f_{\mathrm{PA}}, 0.12$ ). The PA conversions at the identical reaction time of $1.5 \mathrm{~h}$ increased gradually from $50 \%$ to $63 \%$ upon increasing the ethanol feeding amount from 5.0 to $20 \mathrm{mg}$, and the $f_{\mathrm{PA}}$ values also increased gradually from 0.18 to 0.25 (entries 8-11). Because of the faster PA consumption, full PA conversion was achieved in $2.5 \mathrm{~h}$ (entry 13). At this full conversion, the polymerization solution was stirrable because of the formation of a low-molecular-weight polymer. By running the polymerization for a further 1.0 or $2.0 \mathrm{~h}$, the yields increased further from $5.7 \mathrm{~g}$ to 6.4 and $7.0 \mathrm{~g}$, respectively (entries 14, 15). During the additional polymerization time after full PA conversion, only the carbonate units were grown, resulting in the formation of a block copolymer. One side of the block copolymer was gradient poly(1,2-propylene phthalate-cocarbonate), while the other side was poly(1,2-propylene carbonate). When $2.0 \mathrm{~g}$ of PA was fed along with $15 \mathrm{mg}$ of ethanol, full conversion of PA was achieved in $3.0 \mathrm{~h}$ and the $f_{\mathrm{PA}}$ value (0.24) was almost twice that attained at a PA feed of $1.0 \mathrm{~g}$ (entry 16).

When a substantial number of PA units $\left(f_{\mathrm{PA}}, 0.23\right)$ was incorporated in $\mathrm{PO} / \mathrm{CO}_{2} / \mathrm{PA}$ terpolymers, a high $T_{\mathrm{g}}$ of $48{ }^{\circ} \mathrm{C}$ was observed (entries 2 and 7), which was higher than that of the $\mathrm{PO} / \mathrm{CO}_{2}$ alternating copolymer $\left(40{ }^{\circ} \mathrm{C}\right)$, but lower than that of the $\mathrm{PO} / \mathrm{PA}$ alternating polymer $\left(65^{\circ} \mathrm{C}\right)$ (Figure 3$)$. With a small number of incorporated PA units $\left(f_{\mathrm{PA}}\right.$, ca. 0.1$), T_{\mathrm{g}}$ was similar to that of the $\mathrm{PO} / \mathrm{CO}_{2}$ alternating copolymer (entries 4, 13-15). For the polymers generated at the early stage $(1.5 \mathrm{~h})$, two $T_{\mathrm{g}}$ signals were observed at $25{ }^{\circ} \mathrm{C}$ and ca. $70{ }^{\circ} \mathrm{C}$ (entries 1,5 , $8-10)$.

In the polymerization reaction, the nitrate and acetate anions in 1 became chain-growing carbonate or alkoxide anions [14,17]. In the presence of protic compounds such as water (present as an impurity) or alcohols (deliberately added), reversible proton exchange reactions occur rapidly between the chain-growing

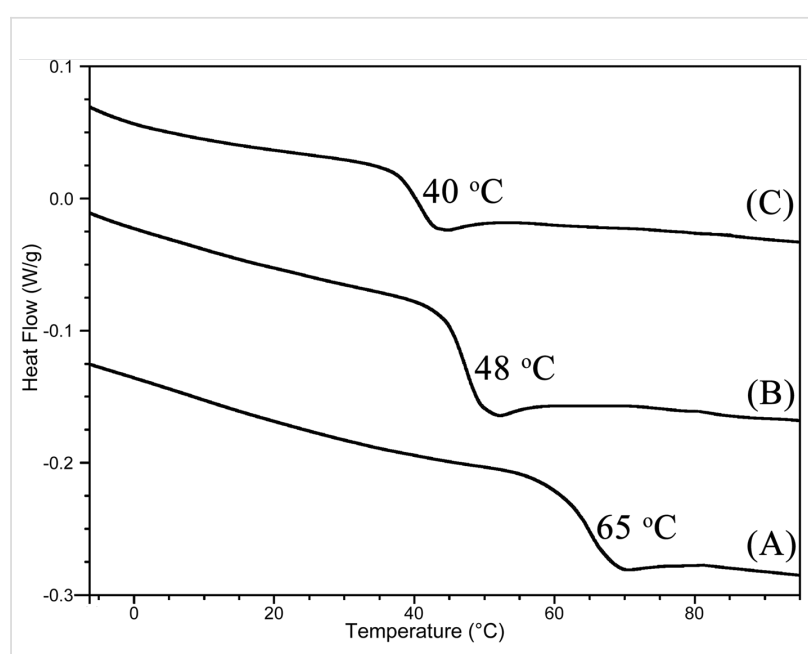

Figure 3: DSC curves of PO/PA alternating polymer (A, entry 1 in Table 1), $\mathrm{PO} / \mathrm{CO}_{2} / \mathrm{PA}$ terpolymer (B, entry 7 in Table 2 ), and $\mathrm{PO} / \mathrm{CO}_{2}$ alternating copolymer (C).

anions and protic compounds, resulting in uniform chain growth not only from the protic compounds but also from the anions in 1. In all cases, when the polymerizations were carried out without the deliberate addition of a chain-transfer agent (Table 2, entries 1-7), bimodal GPC curves were observed (see Supporting Information File 1). Polymer chains in the highmolecular-weight mode were grown biaxially from water, while those in the low-molecular-weight mode were grown from the anions in $\mathbf{1}$. The ratio of the two modes was different for each entry. A very small amount of catalyst $\mathbf{1}$ was fed under the polymerization conditions employed $(\mathbf{1} / \mathrm{PO}=1: 100,000)$, so the number of impurity water molecules was not negligible, and varied in the range of the same order of the number of anions in 1, even with thorough drying of $\mathrm{PO}$ and $\mathrm{CO}_{2}$. High-molecularweight polymers with $M_{\mathrm{n}} 381,000$ and 354,000 were obtained at the full conversions of $1.0 \mathrm{~g}$ and $2.0 \mathrm{~g}$ PA, respectively (Table 2, entries 4 and 7). The molecular weights were controlled by the amount of ethanol fed as a chain-transfer agent. At the feeding amount of $15 \mathrm{mg}$ of ethanol (180 equiv per 1) and full conversion of PA (Table 2, entries 13-16), lowmolecular-weight polymers with $M_{\mathrm{n}} 16,000-26,000$ were generated. The numbers of polymer chains generated per 1 under those conditions were calculated to be 198, 187, 145, and 167, respectively, roughly in agreement with the number of ethanol molecules (180 equiv per 1). For the feeding of a large amount of ethanol (180 equiv per 1), the number of polymer chains grown biaxially from the water molecules was negligible, and very narrow unimodal distributions were observed with $M_{\mathrm{w}} / M_{\mathrm{n}}$ of ca. 1.05 in the GPC curves.

Scheme 4 shows the PA incorporation process in the $\mathrm{PO} / \mathrm{CO}_{2} /$ $\mathrm{PA}$ terpolymerizations. In addition to the direct attack of the 
alkoxide anion on PA, another PA consumption process might operate in the presence of the chain transfer agent such as deliberated added ethanol or impurity water. In this process, PA directly reacted with the formed $\mathrm{OH}$ chain terminus, leading to incorporation of PA without the action of the catalyst. This process made the PA conversion faster, consequently helping to achieve the full conversion of PA.

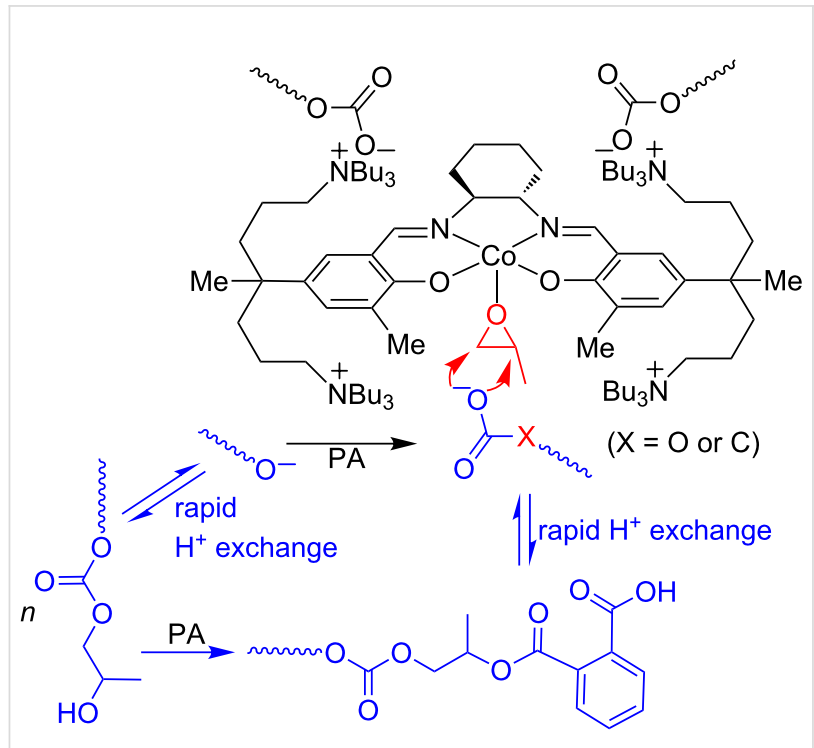

Scheme 4: PA incorporation process in $\mathrm{PO} / \mathrm{CO}_{2} / \mathrm{PA}$ terpolymerization.

\section{Conclusion}

The (salen)Co(III) complex 1 tethering four quaternary ammonium salts, which is a highly active catalyst for $\mathrm{CO}_{2} / \mathrm{PO}$ copolymerization, worked efficiently as a catalyst in both $\mathrm{PO} / \mathrm{PA}$ copolymerizations and $\mathrm{CO}_{2} / \mathrm{PO} / \mathrm{PA}$ terpolymerizations. An attractive feature in view of commercial application is that full conversion of PA could be achieved within $5 \mathrm{~h}$ in both polymerizations, even under the conditions of a high feeding amount of PA (2.0 g PA/10 g PO) and a very small feeding amount of catalyst $1(3.0 \mathrm{mg})$. No ether linkages were formed in either of the polymerizations to afford poly(1,2-propylene phthalate) or poly(1,2-propylene phthalate-co-carbonate). The latter had a gradient composition with one end enriched with PA units and the other enriched with carbonate units. Both showed immortal polymerization character: the molecular weights of the resulting polymer were controlled precisely by the activity ( $\mathrm{g} / \mathrm{mol}-\mathbf{1})$ and the number of chain-growing sites per $\mathbf{1}$ [anions in $\mathbf{1}(5)+$ water (present as impurity) + ethanol (deliberately fed)], and the molecular weight distributions were narrow $\left(M_{\mathrm{w}} / M_{\mathrm{n}}, 1.05-1.5\right)$ Because of the high activity of $\mathbf{1}$, polymers with very high molecular weights were generated $\left(M_{\mathrm{n}}\right.$ up to 170,000 and 350,000 for $\mathrm{PO} / \mathrm{PA}$ copolymerization and $\mathrm{CO}_{2} / \mathrm{PO} / \mathrm{PA}$ terpolymerization, respectively). The terpolymer bearing a substantial number of PA units $\left(f_{\mathrm{PA}}, 0.23\right)$ showed a higher $T_{\mathrm{g}}$ value $\left(48{ }^{\circ} \mathrm{C}\right)$ than the $\mathrm{CO}_{2} / \mathrm{PO}$ alternating copolymer $\left(40{ }^{\circ} \mathrm{C}\right)$.

\section{Experimental}

General remarks. $\mathrm{CO}_{2}$ gas $(99.999 \%$ purity) was dried through storage in a column of molecular sieves $3 \AA$ at a pressure of 30 bar. PO was dried by stirring over $\mathrm{CaH}_{2}$ and then vacuum-transferred to a reservoir. PA was purchased from Aldrich and purified by recrystallization in ethyl acetate. ${ }^{1} \mathrm{H}$ NMR (400 MHz) and ${ }^{13} \mathrm{C}$ NMR (100 MHz) spectra were recorded on a Varian Mercury Plus 400 instrument. Gel permeation chromatography (GPC) was performed in THF at $40{ }^{\circ} \mathrm{C}$ using a Waters Millennium apparatus with polystyrene standards. The $T_{\mathrm{g}}$ data were determined from a second heating at a heating rate of $10{ }^{\circ} \mathrm{C} / \mathrm{min}$ by differential scanning calorimetry (DSC) using a Thermal Analysis Q10 instrument.

Typical procedure for $\mathrm{PO} / \mathrm{PA}$ alternating copolymerizations. A bomb reactor (ca. $50 \mathrm{~mL}$ ) was assembled inside a glove box after being charged with $\mathbf{1}$ ( $3.0 \mathrm{mg}, 1.8 \mu \mathrm{mol})$, PO (10.4 g, $179 \mathrm{mmol}$ ), and PA (and ethanol as a chain-transfer agent). The reactor was immersed in a hot oil bath $\left(80{ }^{\circ} \mathrm{C}\right)$. After running of the polymerization for a given time, the reactor was cooled to room temperature. An aliquot was taken to measure the PA conversion by ${ }^{1} \mathrm{H}$ NMR spectroscopy. The polymer solution was filtered over a short pad of silica gel to remove the catalyst residue. The silica gel pad was washed with methylene chloride $(10 \mathrm{~mL} \times 2)$. The colorless filtrates were combined. The solvent was removed using a rotary evaporator, and the residual solvent was removed completely by keeping the isolated lump in a vacuum oven overnight at $100{ }^{\circ} \mathrm{C}$. When the PA conversion was not $100 \%$, the polymer was obtained admixed with unreacted PA. For DSC studies, small pieces of the polymer lump admixed with the unreacted PA were dissolved in a copious amount of $\mathrm{CH}_{2} \mathrm{Cl}_{2}$, and the resulting solution was eluted through a relatively long pad of silica gel.

Typical procedure for $\mathrm{PO} / \mathrm{CO}_{2} / \mathrm{PA}$ terpolymerizations. A bomb reactor (ca. $50 \mathrm{~mL}$ ) was assembled inside a dry box after being charged with $1(3.0 \mathrm{mg}, 1.8 \mu \mathrm{mol})$, PO (10.4 g, $179 \mathrm{mmol}$ ), and PA (and ethanol as a chain-transfer agent). The $\mathrm{CO}_{2}$ gas was pressurized to $25 \mathrm{bar}$ at room temperature, and the reactor was then immersed in a hot oil bath $\left(80^{\circ} \mathrm{C}\right)$. When the temperature inside the bomb reactor reached the bath temperature, the pressure was 35 bar. After running of the polymerization for a given time, the reactor was cooled to room temperature through immersion in an ice bath. $\mathrm{CO}_{2}$ gas was released and the reactor was opened. An aliquot was taken to measure the PA conversion by ${ }^{1} \mathrm{H}$ NMR spectroscopy. The catalyst removal and work-up procedures were as described for the $\mathrm{PO} /$ PA alternating copolymerizations. 


\section{Supporting Information}

\section{Supporting Information File 1}

${ }^{1} \mathrm{H}$ NMR spectra, ${ }^{13} \mathrm{C}$ NMR spectra, GPC curves, and the pictures of the isolated polymers in $\mathrm{PO} / \mathrm{PA}$ alternating polymerizations and $\mathrm{PO} / \mathrm{CO}_{2} / \mathrm{PA}$ terpolymerizations. [http://www.beilstein-journals.org/bjoc/content/ supplementary/1860-5397-10-187-S1.pdf]

\section{Acknowledgements}

This work was supported by a Korea CCS R\&D Center (KCRC) grant (No. 2012-0008935) funded by the Korea Ministry of Science, ICT and Future Planning, and by a grant from the Fundamental R\&D Program for Integrated Technology of Industrial Materials funded by the Korea Ministry of Knowledge Economy.

\section{References}

1. Darensbourg, D. J.; Wilson, S. J. Green Chem. 2012, 14, 2665-2671. doi:10.1039/c2gc35928f

2. Lu, X.-B.; Ren, W.-M.; Wu, G.-P. Acc. Chem. Res. 2012, 45, 1721-1735. doi:10.1021/ar300035z

3. Klaus, S.; Lehenmeier, M. W.; Anderson, C. E.; Rieger, B. Coord. Chem. Rev. 2011, 255, 1460-1479. doi:10.1016/j.ccr.2010.12.002

4. Kember, M. R.; Buchard, A.; Williams, C. K. Chem. Commun. 2011, 47, 141-163. doi:10.1039/c0cc02207a

5. Luinstra, G. A. Polym. Rev. 2008, 48, 192-219. doi:10.1080/15583720701834240

6. Coates, G. W.; Moore, D. R. Angew. Chem., Int. Ed. 2004, 43, 6618-6639. doi:10.1002/anie.200460442

7. Inoue, S.; Koinuma, H.; Tsuruta, T. J. Polym. Sci., Part B: Polym. Lett. 1969, 7, 287-292. doi:10.1002/pol.1969.110070408

8. Noh, E. K.; Na, S. J.; S, S.; Kim, S.-W.; Lee, B. Y. J. Am. Chem. Soc. 2007, 129, 8082-8083. doi:10.1021/ja071290n

9. S, S.; Min, J. K.; Seong, J. E.; Na, S. J.; Lee, B. Y. Angew. Chem., Int. Ed. 2008, 47, 7306-7309. doi:10.1002/anie.200801852

10. Na, S. J.; S., S.; Cyriac, A.; Kim, B. E.; Yoo, J.; Kang, Y. K.; Han, S. J.; Lee, C.; Lee, B. Y. Inorg. Chem. 2009, 48, 10455-10465. doi:10.1021/ic901584u

11. Nakano, K.; Kamada, T.; Nozaki, K. Angew. Chem., Int. Ed. 2006, 45, 7274-7277. doi:10.1002/anie.200603132

12. Ren, W.-M.; Liu, Z.-W.; Wen, Y.-Q.; Zhang, R.; Lu, X.-B. J. Am. Chem. Soc. 2009, 131, 11509-11518. doi:10.1021/ja9033999

13. Ok, M. A.; Jeon, M. In ANTEC 2011 plastics: 69th Annual technical Conference Proceedings, Boston, Massachusetts, USA, May 1-5, 2011; Society of Plastics Engineers, 2011; pp 2134-2139.

14. Cyriac, A.; Lee, S. H.; Varghese, J. K.; Park, E. S.; Park, J. H.; Lee, B. Y. Macromolecules 2010, 43, 7398-7401. doi:10.1021/ma101259k

15. Jeon, J. Y.; Varghese, J. K.; Park, J. H.; Lee, S. H.; Lee, B. Y. Eur. J. Org. Chem. 2012, 3566-3569. doi:10.1002/ejoc.201200370
16. Min, J.; Seong, J. E.; Na, S. J.; Cyriac, A.; Lee, B. Y. Bull. Korean Chem. Soc. 2009, 30, 745-748. doi:10.5012/bkcs.2009.30.3.745

17. Cyriac, A.; Lee, S. H.; Lee, B. Y. Polym. Chem. 2011, 2, 950-956. doi:10.1039/c0py00365d

18. Cyriac, A.; Lee, S. H.; Varghese, J. K.; Park, J. H.; Jeon, J. Y.; Kim, S. J.; Lee, B. Y. Green Chem. 2011, 13, 3469-3475. doi:10.1039/c1gc15722a

19. Lee, S. H.; Cyriac, A.; Jeon, J. Y.; Lee, B. Y. Polym. Chem. 2012, 3, 1215-1220. doi:10.1039/c2py00010e

20. Langanke, J.; Wolf, A.; Hofmann, J.; Böhm, K.; Subhani, M. A. Müller, T. E.; Leitner, W.; Gürtler, C. Green Chem. 2014, 16 1865-1870. doi:10.1039/c3gc41788c

21. Varghese, J. K.; Park, D. S.; Jeon, J. Y.; Lee, B. Y. J. Polym. Sci., Part A: Polym. Chem. 2013, 51, 4811-4818. doi:10.1002/pola.26905

22. Gao, Y.; Gu, L.; Qin, Y.; Wang, X.; Wang, F. J. Polym. Sci., Part A: Polym. Chem. 2012, 50, 5177-5184. doi:10.1002/pola.26366

23. Jeon, J. Y.; Lee, J. J.; Varghese, J. K.; Na, S. J.; Sujith, S.; Go, M. J.; Lee, J.; Ok, M. A.; Lee, B. Y. Dalton Trans. 2013, 42, 9245-9254. doi:10.1039/c2dt31854g

24. Seong, J. E.; Na, S. J.; Cyriac, A.; Kim, B. W.; Lee, B. Y. Macromolecules 2009, 43, 903-908. doi:10.1021/ma902162n

25. Ren, W.-M.; Zhang, X.; Liu, Y.; Li, J.-F.; Wang, H.; Lu, X.-B. Macromolecules 2010, 43, 1396-1402. doi:10.1021/ma902321g

26. DiCiccio, A. M.; Coates, G. W. J. Am. Chem. Soc. 2011, 133, 10724-10727. doi:10.1021/ja203520p

27. Jeske, R. C.; DiCiccio, A. M.; Coates, G. W. J. Am. Chem. Soc. 2007, 129, 11330-11331. doi:10.1021/ja0737568

28. Liu, Y.; Xiao, M.; Wang, S.; Xia, L.; Hang, D.; Cui, G.; Meng, Y. RSC Adv. 2014, 4, 9503-9508. doi:10.1039/c3ra46343e

29. Jeske, R. C.; Rowley, J. M.; Coates, G. W. Angew. Chem., Int. Ed. 2008, 47, 6041-6044. doi:10.1002/anie.200801415

30. Bernard, A.; Chatterjee, C.; Chisholm, M. H. Polymer 2013, 54, 2639-2646. doi:10.1016/j.polymer.2013.02.033

31.Song, P. F.; Xiao, M.; Du, F. G.; Wang, S. J.; Gan, L. Q.; Liu, G. Q.; Meng, Y. Z. J. Appl. Polym. Sci. 2008, 109, 4121-4129. doi:10.1002/app.28449

32. Varghese, J. K.; Na, S. J.; Park, J. H.; Woo, D.; Yang, I.; Lee, B. Y. Polym. Degrad. Stab. 2010, 95, 1039-1044. doi:10.1016/j.polymdegradstab.2010.03.006

33. Nakano, K.; Hashimoto, S.; Nakamura, M.; Kamada, T.; Nozaki, K. Angew. Chem., Int. Ed. 2011, 50, 4868-4871. doi:10.1002/anie.201007958

34. Lee, B. Y.; Cyriac, A. Nat. Chem. 2011, 3, 505-507. doi:10.1038/nchem.1081

35. Lee, J. J.; Jeon, J. Y.; Park, J. H.; Jang, Y.; Hwang, E. Y.; Lee, B. Y. RSC Adv. 2013, 3, 25823-25829. doi:10.1039/c3ra45264f

36. Park, J. H.; Jeon, J. Y.; Lee, J. J.; Jang, Y.; Varghese, J. K.; Lee, B. Y. Macromolecules 2013, 46, 3301-3308. doi:10.1021/ma400360w 


\section{License and Terms}

This is an Open Access article under the terms of the Creative Commons Attribution License

(http://creativecommons.org/licenses/by/2.0), which permits unrestricted use, distribution, and reproduction in any medium, provided the original work is properly cited.

The license is subject to the Beilstein Journal of Organic Chemistry terms and conditions:

(http://www.beilstein-journals.org/bjoc)

The definitive version of this article is the electronic one which can be found at:

doi:10.3762/bjoc. 10.187 